\title{
Technical Tip: A Simple Method for Proper Placement of an Intramedullary Nail Entry Point for Tibiotalocalcaneal or Tibiocalcaneal Arthrodesis
}

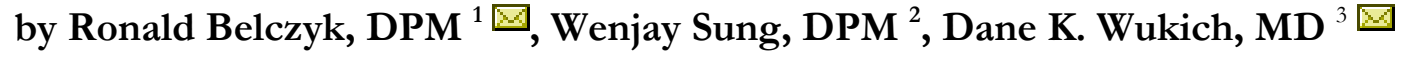

The Foot \& Ankle Journal 1 (9): 4

The purpose of this article is to report on a technical tip when performing tibiotalocalcaneal or tibiocalcaneal arthrodesis. Technical faults of this arthrodesis may include malpositioning of the IM nail that can potentiate complications such as nonunion, delayed union, malunion, screw fracture, painful hardware, fracture of the intramedullary nail, tibial fracture, wound healing complications, and nerve damage. This article will present important information to aid the surgeon in preventing malpositioning of an IM nail and will provide a simple clinical pearl for perioperative incisional planning using image intensification.

Key words: Tibiotalocalcaneal fusion, Tibiocalcaneal fusion, IM nail, Intramedullary rod, complications

Accepted: July 2008 Published: September 2008

This is an Open Access article distributed under the terms of the Creative Commons Attribution License. It permits unrestricted use, distribution, and reproduction in any medium, provided the original work is properly cited. @The Foot \& Ankle Journal (www.faoj.org)

Several authors have reported the use of intramedullary (IM) nails in ankle and hindfoot arthrodesis with varying rates of success and complications. ${ }^{1,5,7,12}$ Since intramedullary nailing involves arthrodeses of the ankle and hindfoot, accurate entry point placement is a critical step with this procedure. Although many technical pearls of initial guide-wire placement have been described in the literature, we have nonetheless seen complications arising from malpositioning. ${ }^{1-3}$

\footnotetext{
Address correspondence to: Dane Wukich, MD. UPMC

Comprehensive Foot and Ankle Center. Roesch-Taylor Bldg Ste 7300.

2100 Jane St. Pittsburgh, PA 15203. Phone: 412-586-1546 Fax: 412-

586-1544

Email: wukichdk@upmc.edu

${ }^{1}$ PGY-4, Fellow, Foot and Ankle Surgery, University of Pittsburgh Medical Center, Pittsburgh, Pennsylvania, 15203.

${ }^{2}$ Resident, Foot and Ankle Surgery, University of Pittsburgh Medical Center, Pittsburgh, Pennsylvania, 15203.

${ }^{3}$ Chief, Foot and Ankle Division, University of Pittsburgh Medical Center Department of Orthopedic Surgery and Assistant Professor, University of Pittsburgh School of Medicine, Pittsburgh, Pennsylvania, 15203.
}

This manuscript reviews potential complications associated with intramedullary nailing, in particular to malpositioning of the retrograde nail. We present two cases that presented with continued pain upon ambulation after attempted tibiotalocalcaneal fusions. Their nonunion and failure of fixation was related in part due to malpositioning of the intramedullary nail. This article further reviews several authors' recommendations for determining the ideal entry point for the insertion of an intramedullary nail for tibiotalocalcaneal fusion. Many of these studies recommend a guide wire entry point based on anatomical landmarks and preoperative radiographic findings.

Lastly, this article will describe a simple method of perioperative incisional planning by using image intensification. 


\begin{tabular}{|l|l|}
\hline Table 1: Reported Complications of IM nailing \\
\hline Reference & Complications \\
\hline Kile (1994) & $2 / 30$ no radiographic or clinical union \\
& $2 / 30$ went on to below knee amputation \\
\hline Buratti (1994) & $1 / 5$ fracture of calcaneal-talar-tibial screw \\
\hline Flock (1997) & $42 \%$ risk of damaging the nerve to the adductor digiti quinti \\
\hline Thordarson (1999) & $\begin{array}{l}2 / 12 \text { nondisplaced stress fracture around the proximal interlocking screws } \\
7 / 12 \text { cortical hypertrophy around the proximal interlocking screws }\end{array}$ \\
\hline Mader (2003) & $\begin{array}{l}1 / 20 \text { varus malunion } \\
1 / 82 \text { delayed union nonunion } \\
6 / 406 \text { locking screws removed secondary to screw fracture or local subcutaneous irritation } \\
1 / 82 \text { fracture of IM rod } \\
1 / 82 \text { incomplete tibial fracture sustained intraoperatively } \\
<1 \% \text { risk of healing or wound healing complications }\end{array}$ \\
\hline
\end{tabular}

Table 1 Reported complications of IM nailing.

\section{Potential complications}

Potential complications associated with this type of procedure include: nonunion, delayed union, malunion, screw fracture, painful hardware, fracture of the intramedullary nail, tibial fracture, wound healing complications, and nerve damage. ${ }^{4}$ 10 Table 1 summarizes complications encountered by several foot and ankle surgeons.

In addition to those complications listed in table 1 , we present two cases with improperly placed intramedullary nails. Figures 2 and $3 \mathrm{~b}$ are calcaneal axial radiographs which reveal malpositioning of an intramedullary nail.

\section{Case 1}

A 56 year old female with hypothyroidism, diabetes, peripheral neuropathy and a significant history of tobacco use presented to our service with severe pain in the medial aspect of her foot. She had sustained an ankle fracture five years prior and underwent open reduction internal fixation, subsequently developing a valgus deformity of her ankle and Charcot neuroarthropathy. Her ankle and hindfoot deformity was treated with a tibiotalocaneal fusion using a retrograde intramedullary nail. At the time of IM nail removal, movement was seen through the subtalar joint. (Figs.1ab, Fig.2) 


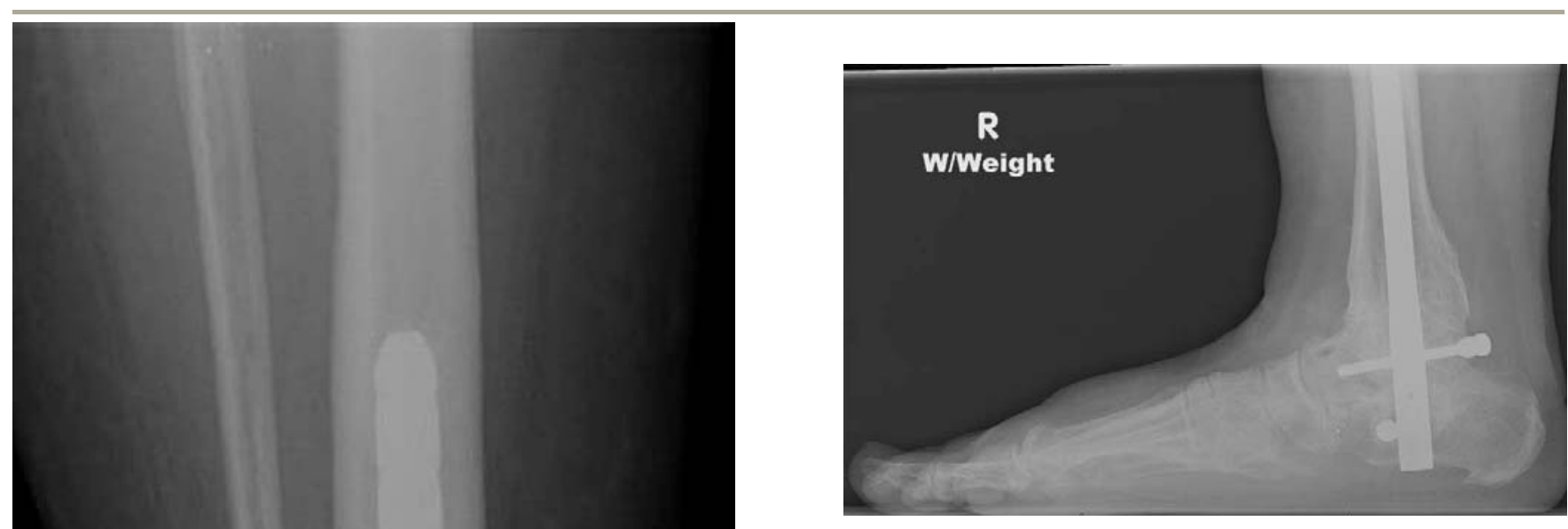

Figure 1b Case 1: Lateral ankle radiographs showing placement of intramedullary nail for the tibiotalocalcaneal arthrodesis.

\section{Case 2}

A 66 year old male with rheumatoid arthritis, diabetes and peripheral neuropathy presented with significant pain upon ambulation. He related a history of a talus fracture that went on to Charcot neuroarthropathy of the ankle and hindfoot. He underwent a tibiotalocalcaneal fusion with intramedullary nail two years prior to our initial consultation. Figures 3abc demonstrate the patient's initial presenting radiographs. The radiographs reveal distal migration of the IM nail. A computerized tomography (CT) scan showed a nonunion of the tibiocalcaneal joint. Laboratory data revealed no clinical signs of infection. Revisional arthrodesis was performed using circular ring fixation and external bone stimulation.

Figure 1a Case 1: Anteroposterior (AP) ankle radiographs showing an intramedullary nail for a tibiotalocalcaneal arthrodesis. 


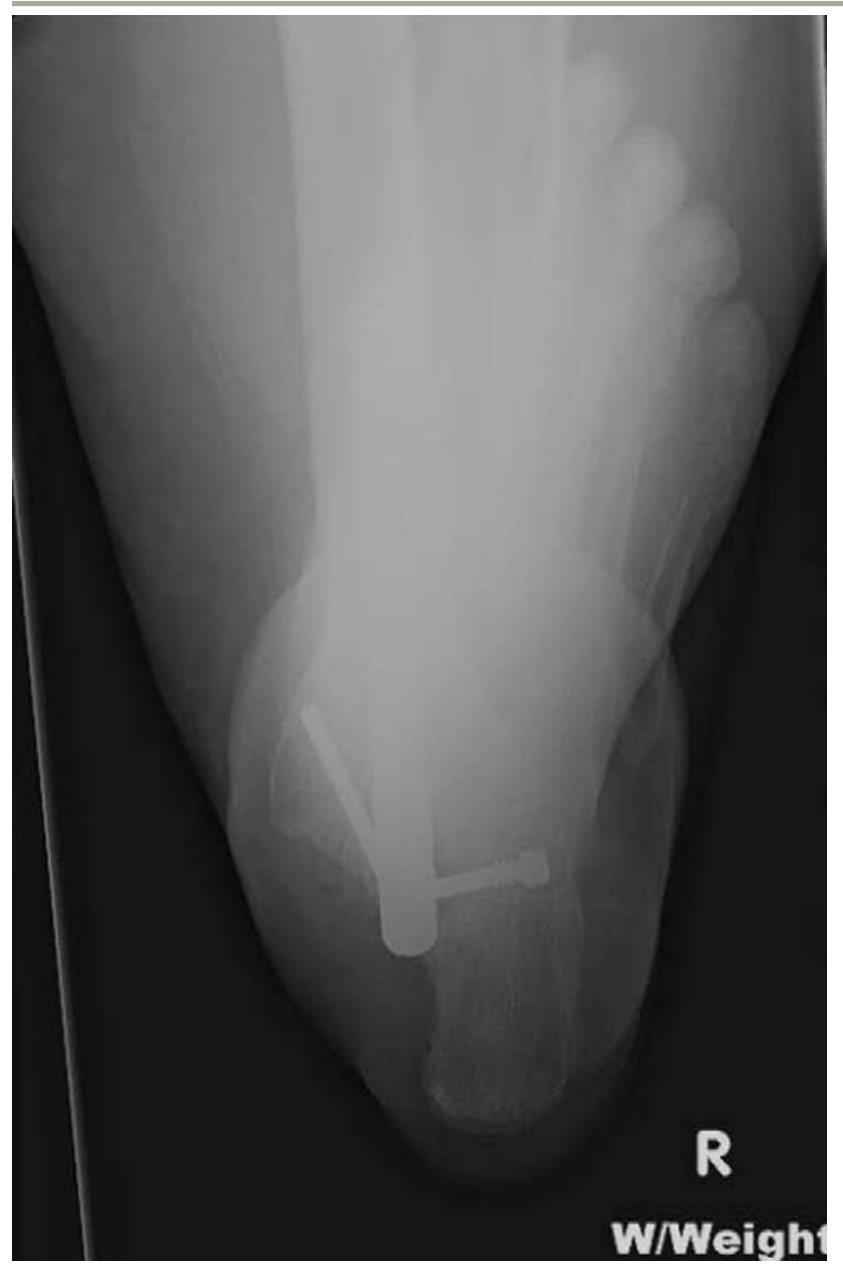

Figure 2 Case 1: Calcaneal Axial radiograph demonstrating malpositioning of the IM nail through the hindfoot with the insertion site too medial.

\section{Recommendations for determining guide wire entry point}

Accurate guide wire placement is critical prior to reaming and inserting a retrograde intramedullary nail for tibiotalocalcaneal or tibiocalcaneal fusion. The guide wire is typically placed into the central medial aspect of the calcaneus and centered in the medullary canal of the tibia. Because the longitudinal bisection of the calcaneus is lateral relative to the alignment of the tibia in a normal anatomic structure, it is usually necessary to medially translate the talus and calcaneus.

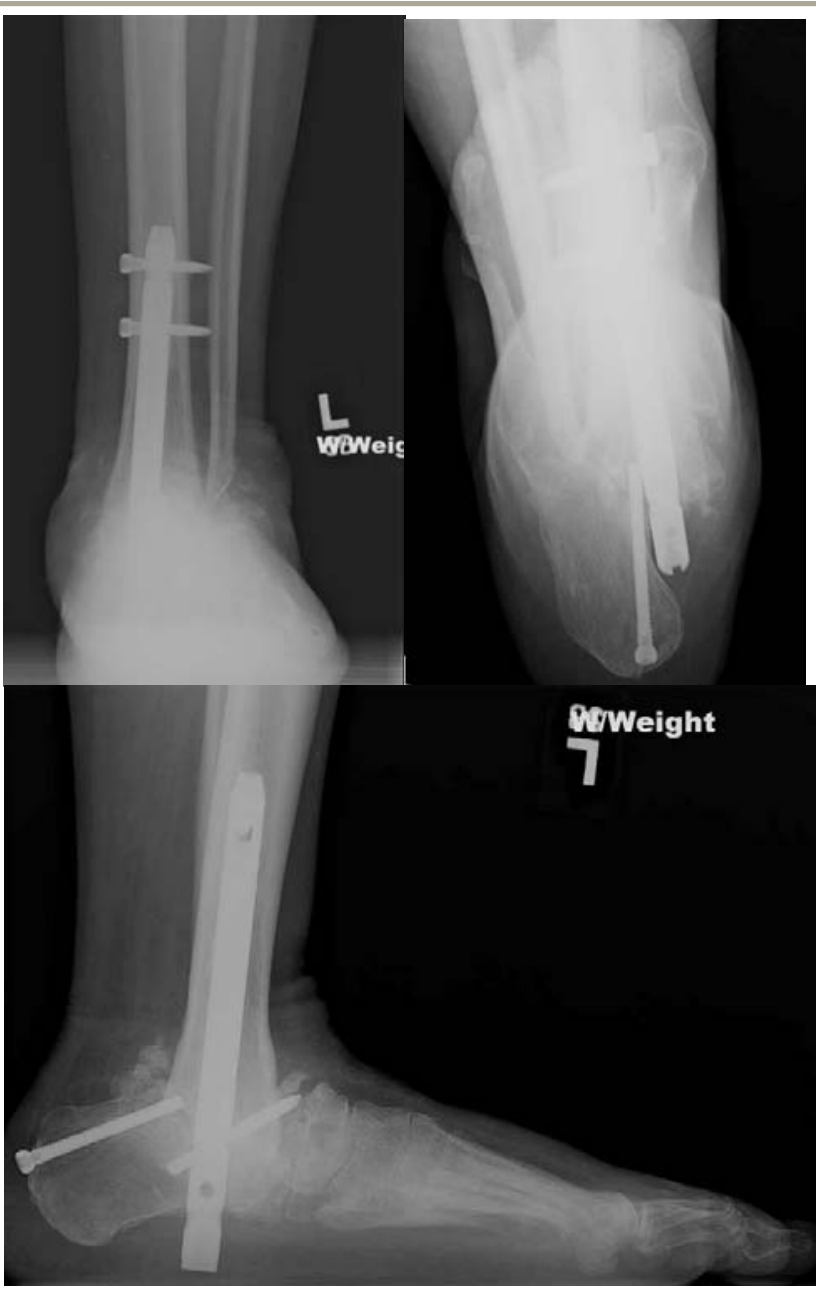

Figure 3abc Case 2: AP (a), axial (b) and Lateral (c) radiographs of the ankle demonstrate an attempted tibiocalcaneal fusion with an intramedullary nail with broken calcaneal screw and distal migration of the nail.

This will allow insertion of a straight nail from the calcaneus into the central portion of the tibia. ${ }^{11}$

The foot placement should be 90 degrees with respect to the lower leg, maintaining the heel in neutral position with 10-15 degrees of external rotation. Blunt dissection is carried down to the bone to avoid any neurovascular structures. ${ }^{13}$ 


\begin{tabular}{|c|c|}
\hline Reference & Recommendation \\
\hline Quill (2003) & $\begin{array}{l}\text { A } 3 \mathrm{~cm} \text { longitudinal plantar incision is made anterior to subcalcaneal fat pad and slightly lateral to the } \\
\text { midline, especially in patients with preoperative valgus. The ideal position for the plantar calcaneal entry } \\
\text { site is anterior to the weight- bearing surface of the calcaneal tuberosity and approximately } 2 \mathrm{~cm} \text { posterior } \\
\text { to the articulation of the calcaneus with the transverse tarsal joint. }\end{array}$ \\
\hline Mader (2003) & $\begin{array}{l}\text { A } 2.5 \mathrm{~cm} \text { incision is made in the foot over the center of the tuberosity of the calcaneus, and blunt } \\
\text { dissection is extended to its plantar surface. The neurovascular bundle is then protected with Langenbeck } \\
\text { retractors. }\end{array}$ \\
\hline DiDomenico \& Adams (2005) & $\begin{array}{l}\text { Approximately } 3 \mathrm{~cm} \text { distal to the plantar fascial insertion, in direct alignment with the medullary canal of } \\
\text { the tibia. The guide wire should be placed into the central medial aspect of the calcaneus and centered in } \\
\text { the medullary canal of the tibia. }\end{array}$ \\
\hline Roukis (2006) & $\begin{array}{l}\text { The guidewire should be first aligned with the lower leg soft tissue outline, which approximates the } \\
\text { location of the calcaneocuboid joint, and then translated } 2.0 \mathrm{~cm} \text { posteriorly to increase the efficacy of } \\
\text { properly seating the guide wire. This allows more efficient and accurate placement while decreasing } \\
\text { dependency on intraoperative fluoroscopy. }\end{array}$ \\
\hline
\end{tabular}

Table 2 Several recommendations for determining proper IM nail entry points.

A number of authors have described the anatomical placement of the IM nail. Table 2 summarizes several author recommendations for determining the proper entry point. The surgical approach to placement of the IM nail is described in terms of measurement from specific landmarks and anatomical structures.

Our technique uses perioperative imaging to determine the placement of the IM nail. Using intraoperative $\mathrm{C}$-arm visualization, the long axis of the tibia on lateral view is used to determine the tibial location along the plantar entry point of the foot. The IM nail is simply placed along the lateral leg just above the border of the fibula. A marking pen is then used to draw a horizontally placed line along the plantar aspect of the foot. This corresponds to the central tibial component for IM nail placement.
The IM nail should visually appear to go directly through the lateral process of the talus on lateral view.

The second vertical or longitudinal bisecting line is made with the calcaneal axial view perioperatively. The IM nail is placed directly against the plantar heel on axial view. The line corresponds to the valgus or varus rotation of the calcaneus. The marking pen is then used to draw a longitudinal bisecting line. The center of the bisecting line represents the ideal entry point for the IM nail. Here, no measurements are required, and the landmarks to determine the ideal entry point correspond to radiographic anatomical structures. Figures 4-7 show a stepwise approach for perioperative incisional planning. The entry point is based on lateral ankle and calcaneal axial views utilizing $\mathrm{C}$-arm visualization. 


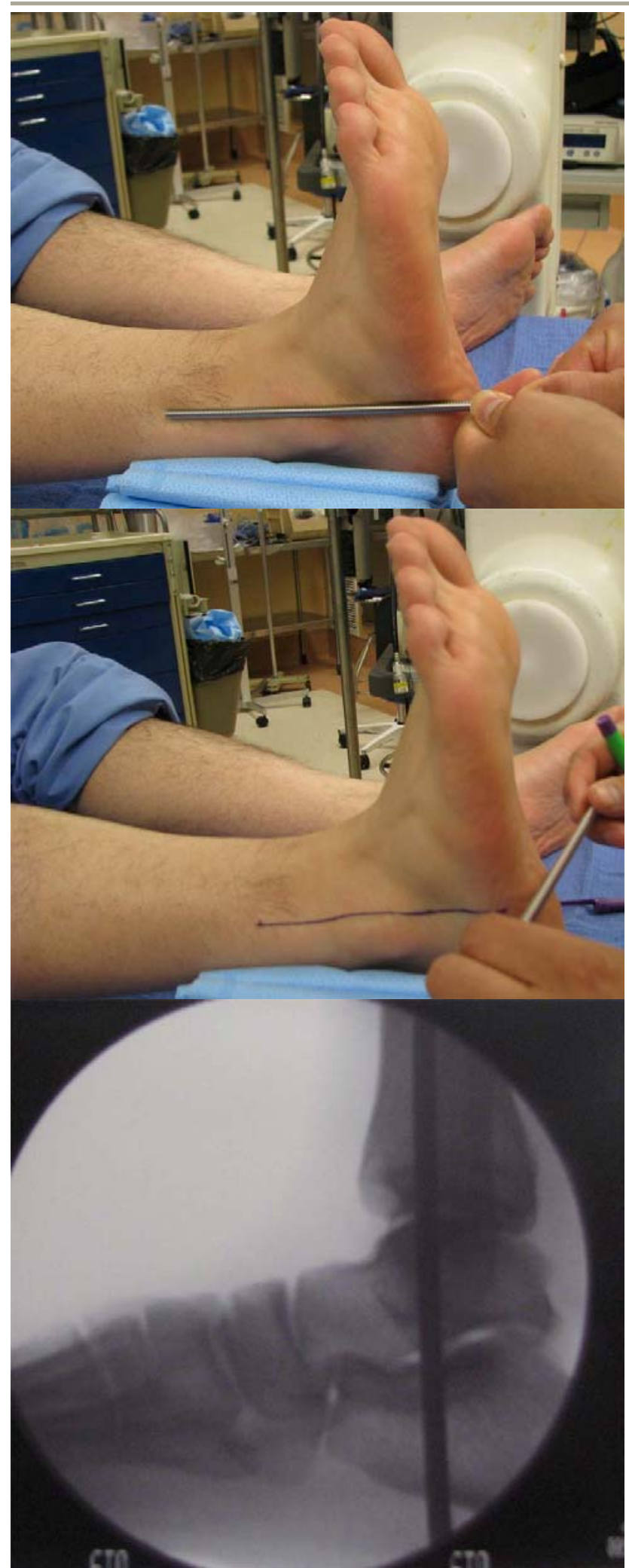

Figure 4abc Preoperatively, a line is made on the ankle which is consistent with a line that bisects the tibia and goes through the lateral talar process.

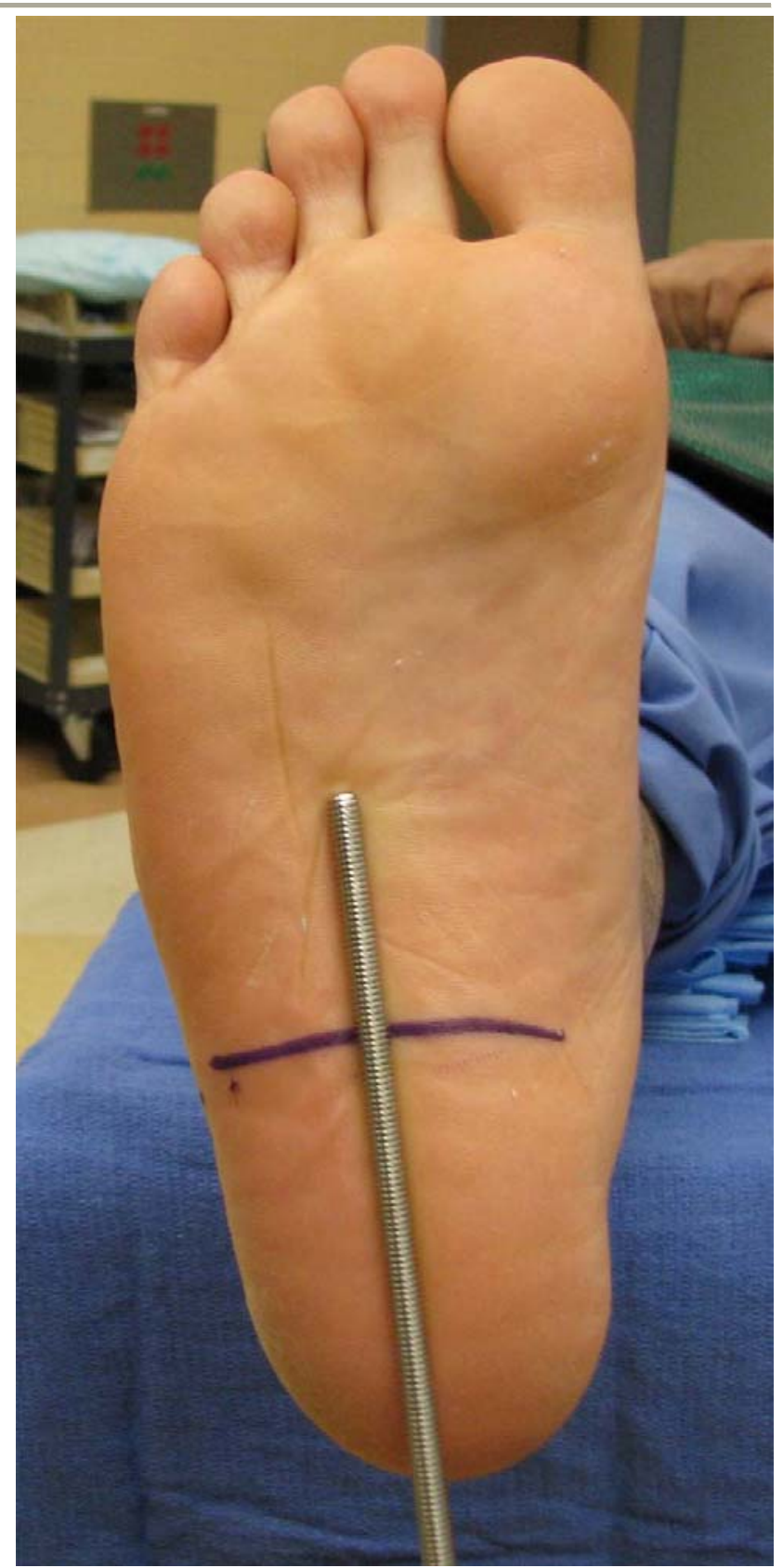

Figure 5 The mark on the lateral aspect of the ankle is then continued transversely on the plantar surface of the foot. A guide-wire or metallic marker, in this case a threaded rod, is then placed against the plantar aspect of the foot along the center of the heel. 


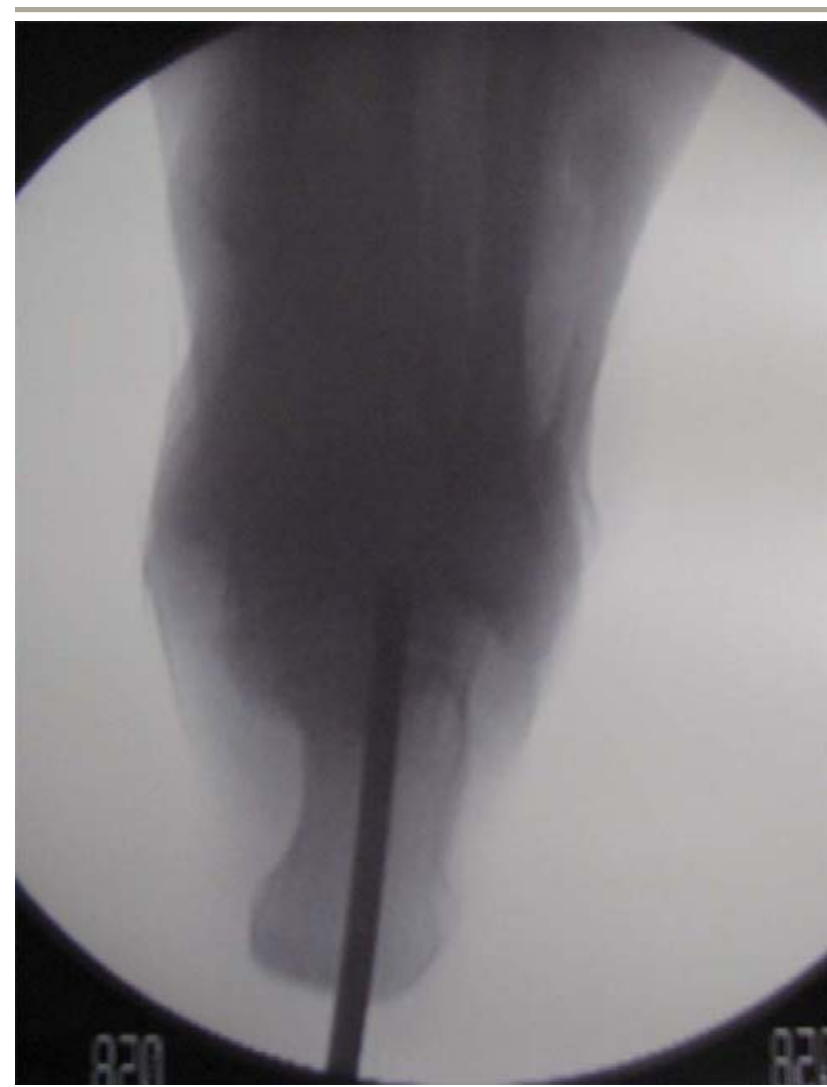

Figure 6 Using image intensification, a calcaneal axial view is taken and a line bisecting the calcaneus is then marked on the plantar skin.

\section{Summary}

In summary, ideal incisional placement permits accurate insertion, good screw purchase, and avoids neurovascular damage. (Fig. 8ab) Although fixed angled devices are being popularized as being able to purchase a greater amount of calcaneus and not having to medially translate the talus to align the tibia and calcaneus, clearly intraoperative errors can lead to postoperative complications as presented in this article. A simple, accurate, and reproducible method of determining the proper entry point as described in this article is invaluable to the foot and ankle surgeon performing tibiotalocalcaneal or tibiocalcaneal fusion with intramedullary devices. Currently there are retrograde devices approved for use that have a valgus orientation built into the nail.

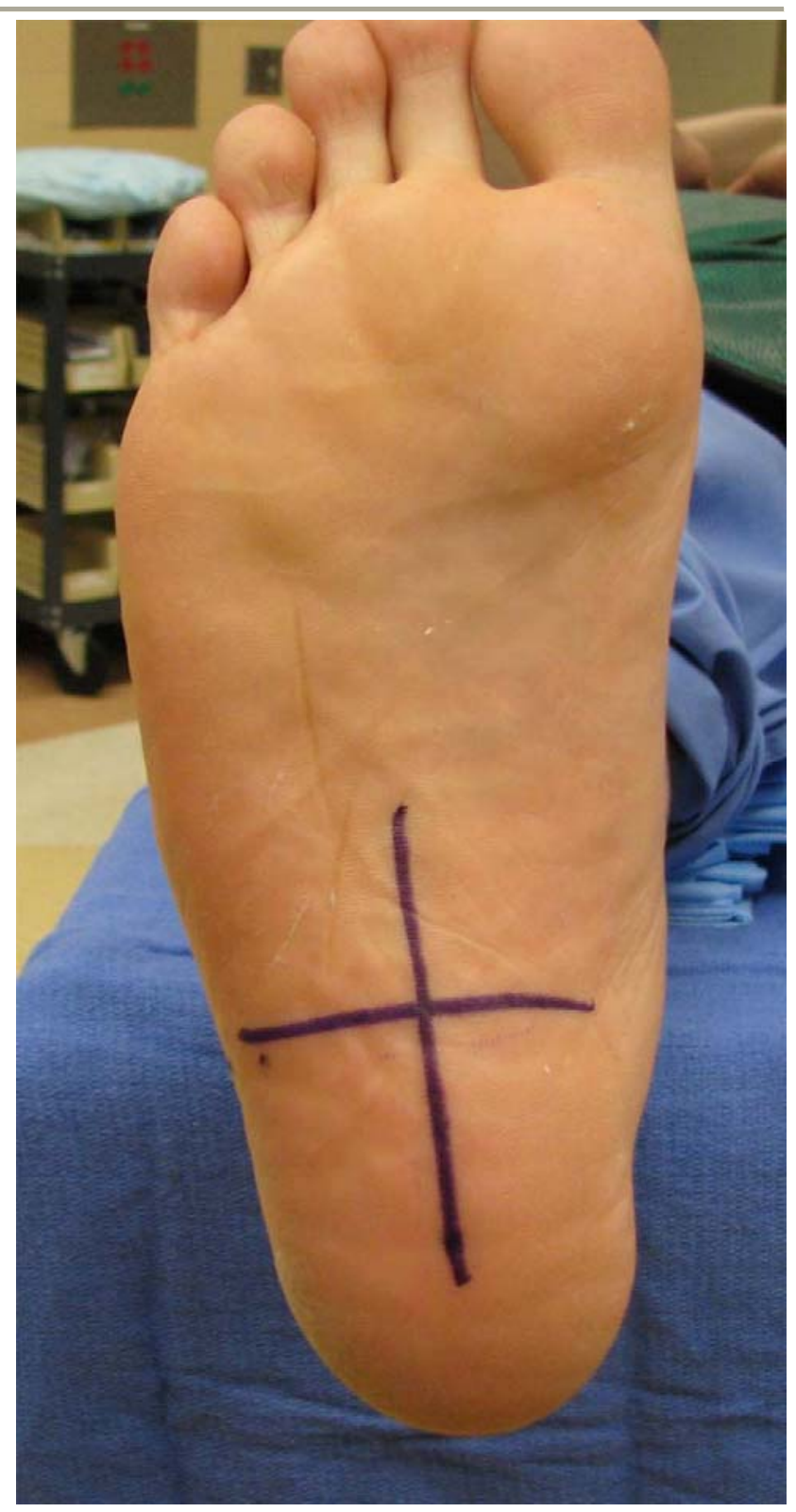

Figure 7 The center of the two intersecting lines is the ideal entry point.

The valgus nail such as the T2 Ankle arthrodesis nail (Stryker, Kalamazoo, MI) or the Hindfoot Arthrodesis Nail-EX (Synthes, West Chester, PA) can facilitate proper entry site placement, however, we recommend the above technique to guide proper placement. Proper placement of the device in the calcaneus improves fixation with the distal interlocking screws whether they be transverse or axial in nature. 


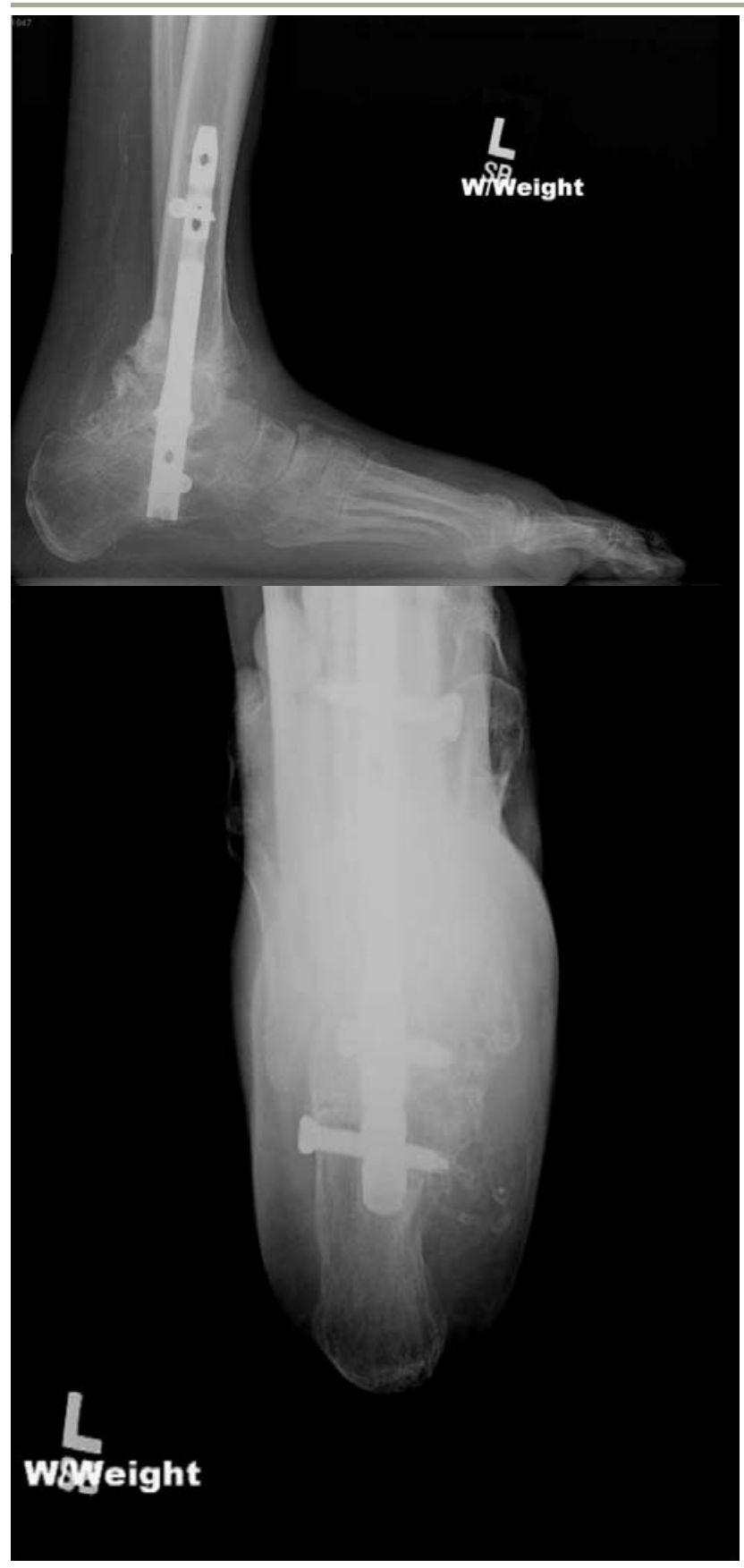

\section{References}

1. Paley D, Herzenberg J, Tetsworth K, McKie J, Bhave A. Deformity planning for frontal and saggittal plane corrective osteotomies. Orthop Clin N Am 25(3):425-465, 1994.

2. Roukis T. Determining the Insertion Site for Retrograde Intramedullary Nail Fixation of Tibiotalocalcaneal Arthrodesis: A Radiographic and Intraoperative Landmark Analysis. J Foot and Ankle Surgery 45(4):227-234, 2006.

3. Lamm B, Paley D. Deformity correction planning for hindfoot, ankle, and lower limb. Clin Podiatr Med Surg 21(3):305-326, 2004.

4. Buratti R, Johnson J, Buratti D. Concurrent ankle and subtalar arthrodesis. J Foot and Ankle Surgery 33(3):278-282, 1994.

5. DiDomenico L, Adams H. Intramedullary nailing for Charcot arthroplasty of the hindfoot and ankle.

Philadelphia: Lippincott Williams and Wilkins Co., 2005. 6. Harvey E, Agel J, Selznick H, Chapman J, Henley M. Deleterious effect of smoking on open tibia-shaft fractures. Am J Orthop 31(9):518-521, 2002.

7. Kile T, Donnelly R, Gehrke J, Werner J, Johnson K.

Tibiotalocalcaneal arthrodesis with an intramedullary device. Foot Ankle Int 15(12):669-673, 1994.

8. Perlman M, Thordarson D. Ankle fusion in a high risk population: an assessment of nonunion risk factors. Foot Ankle Int 20(8):491-496, 1999.

9. Quill G. Tibiotalocalcaneal Arthrodesis with Medullary Rod Fixation. Techniques in Foot and Ankle Surgery 2(2):135143, 2003.

10. Thordarson D, Chang D. Stress fractures andtibial cortical hypertrophy after tibiotalocalcaneal arthrodesis with an intramedullary nail. Foot Ankle Int 20(8):497-500, 1999. 11. McGarvey WC, Trevino SG, Baxter DE, Noble PC, Schon LC. Tibiotalocalcaneal arthrodesis: anatomic and technical considerations. Foot Ankle Int 19(6):363-9, 1998. 12. Singh PJ, Perera NS, Dega R. Measurement of the dose of radiation to the surgeon during surgery to the foot and ankle. J Bone Joint Surg Br 89(8):1060-3, 2007.

13. Flock TJ, Ishikawa S, Hecht PJ, Wapner KL. Heel anatomy for retrograde tibiotalocalcaneal roddings: a roentgenographic and anatomic analysis. Foot Ankle Int 18(4):233-5, 1997.

Figure 8 ab Lateral ankle (a), calcaneal axial (b) radiographs demonstrate a tibiotalocalcaneal fusion with a properly placed intramedullary nail. 